\title{
CORRESPONDENCE
}

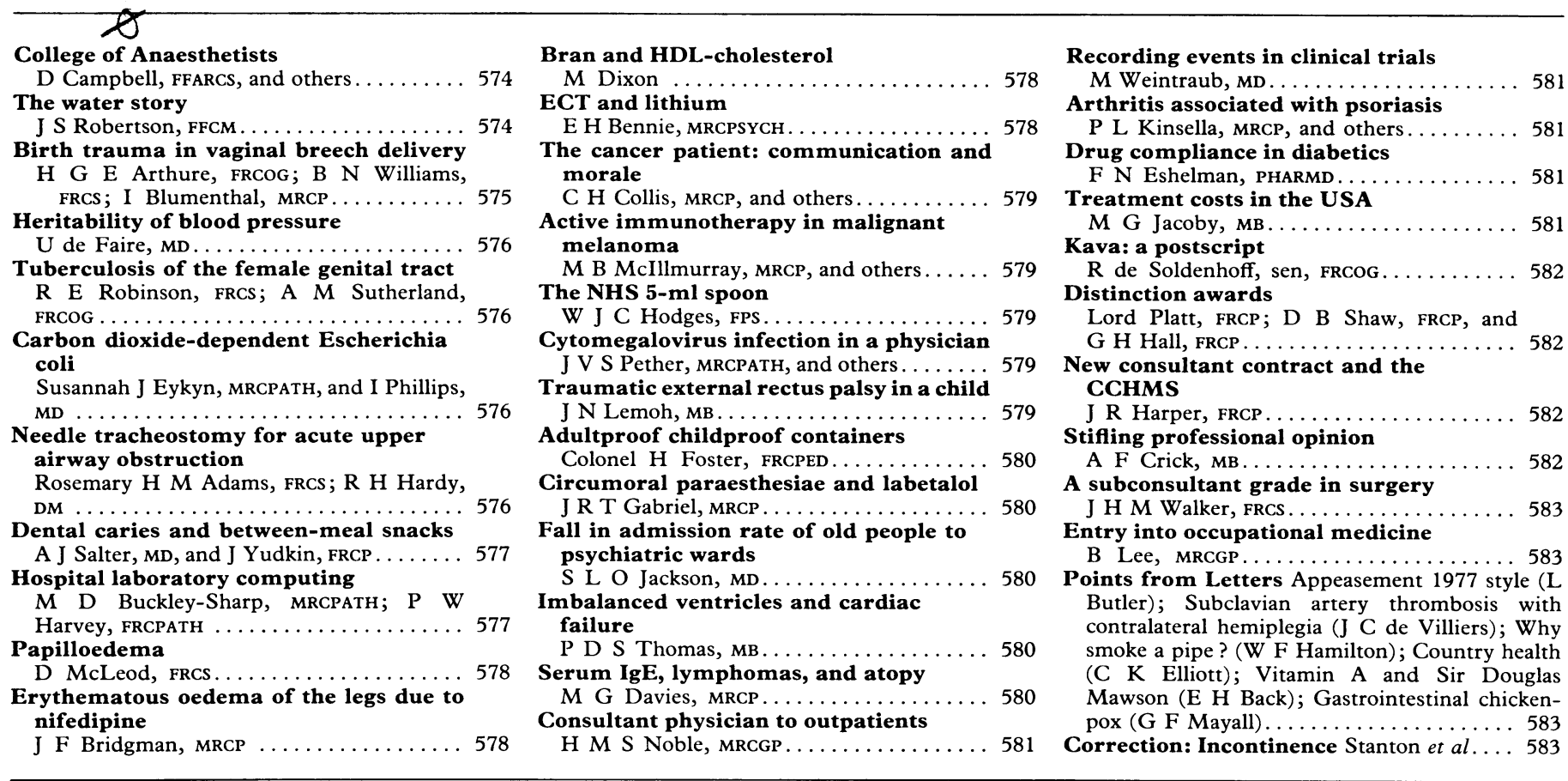

Correspondents are urged to write briefly so that readers may be offered as wide a selection of letters as possible. So many are being received that the omission of some is inevitable. Letters must be signed personally by all their authors.

\section{College of Anaesthetists}

SIR,-Under the sponsorship of the Association of Anaesthetists of Great Britain and Ireland the secretaries of an Anaesthetists Academic Foundation Appeal have written to anaesthetists soliciting funds for a suggested College of Anaesthetists. To members of the association it was sent together with the journal Anaesthesia, in which there was an editorial on the same subject. We find them to be misleading in that they give the impresion that the proposal to found a separate college is generally accepted by anaesthetists.

The letter appears to have been prepared and printed before receipt of the recent communication circulated to fellows of the Royal College of Surgeons of England and its faculties over the signatures of the president and deans. In this it was clearly stated that the new charter of the royal college assured the faculties complete independence in respect of their academic work and their examinations it further provided for three fellows to be elected as full members of Council from each of the faculties, where they have the same franchise and powers and the same access to the highest offices in the college as have the surgical fellows. Indeed, an anaesthetist is at present a vice-president of the college.

In the editorial in Anaesthesia it is stated that "the overwhelming majority of the Council of the Association of Anaesthetists of Great Britain and Ireland believe that the decision must be unequivocally in favour of the foundation of an independent College of Anaesthetists." This must be interpreted against the background that at the 1976 annual general meeting it was clear that there was very far from being an "overwhelming majority" of the members attending in favour of this proposition. It was only on the assurance from the then president, Dr Philip Helliwell, that any proposal to put moneys collected towards the foundation of a college would be brought to a special meeting of the member that it was agreed to launch the appeal.

The editorial went further by suggesting that those favouring the proposal "will wish to ensure that those whom they elect to the Board of Faculty ....will also reflect their views and facilitate a smooth transition to independence." It would seem that this is encouragement to elect to the Board of the Faculty of Anaesthetists those willing to disregard their declaration of loyalty to that body which, in fact, they clearly plan to disrupt. It will not, indeed, be very agreeable to those who have supported the election to the Board of Faculty of fellows whom they believed would act in accord with thei declaration when they proceed to act in a way designed to divert funds from their college and faculty.

We would like it to be known widely among all whom the Association of Anaesthetists may approach for support for this fund both in the profession and in industry that there is a strong body of anaesthetists adamantly opposed to the proposal to take any steps under present circumstances towards the foundation of a separate college. It is certainly our hope that the president and council of the association will respond in a statesmanlike manner to the overtures of the president of the Royal College of Surgeons and the deans of its faculties suggesting a "moratorium" for 10 years on all moves towards this objective.

\section{Donald Campbell Jackson Rees T CeCIL Gray J D Robertson J AlFred Lee J G G Robson E B Lewis Brian SEllick Robert Macintosh JohN UtTing}

\section{The water story}

SIR,-The argument advanced by your two correspondents Dr A Michell and Dr G H B Martin (18 February, p 441) could be sustained only if the effect of the water factor was a long-term one operating by influencing the incidence of severity of atheroma. This is not the case. Although there is ample evidence that mortality is related to the softness of water, there is no evidence of any effect on the incidence of ischaemic heart disease. Indeed, Crawford and Crawford ${ }^{1}$ found more scars from old infarcts in myocardia from London, where the water is hard, than in those from Glasgow, where it is soft. This suggests that the difference in mortality is due to an effect on case fatality rates, recovery from a myocardial infarct being substantially less frequent in residents in soft-water areas. Anderson's observation ${ }^{2}$ that in Canada the difference was confined to sudden deaths reported to the coroner is consistent with this hypothesis.

Before the introduction of artificial softening in 1958 and 1959 the Borough of Scunthorpe experienced the low mortality rates usual in hard-water towns. ${ }^{3}$ As can be seen from the 


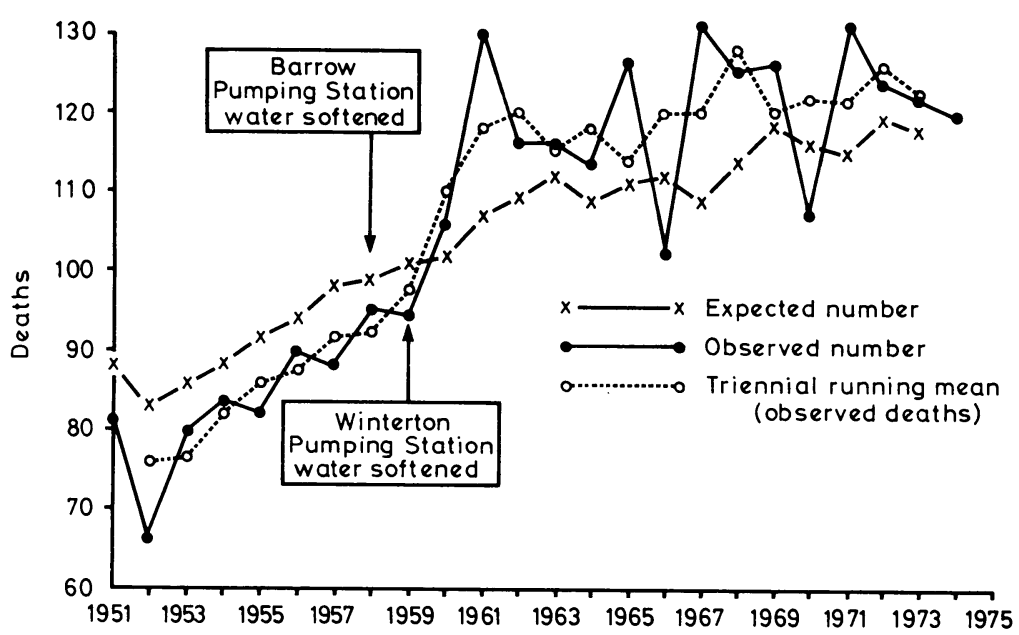

Male deaths, aged 45-64 years, from all causes in Scunthorpe Borough, 1953-75.

accompanying figure, the softening of the town's water supply was followed by an immediate rise in mortality to a level similar to that experienced in towns with soft water. If, as seems likely, these were cause and effect the mechanism must clearly be one which responds to the quality of water currently being used. It is not influenced by the mineral content of water or diet in previous years.

As you indicated in your leading article (4 February, p 264), identification of the water factor will not be easy. More than one element may be involved and the effect may be an indirect one. The mineral content of vegetables is profoundly affected by the hardness of the water in which they are boiled. This may affect their flavour and hence the amount of salt which people feel inclined to add. It is notable that while Dauncey and Widdowson ${ }^{4}$ found no significant difference in the urinary excretion of calcium or magnesium of residents in hard- and soft-water areas, they found that sodium excretion was significantly higher in residents in a soft-water area.

The answer to this riddle is unlikely to come from further epidemiological study. It will require a well-designed experiment such as a controlled trial of mineral supplements, the artificial "hardening" of a major water supply, or a combination of these to show whether calcium, magnesium, lead, or sodium is the "water factor." I believe that we should now be exploring the feasibility of fortifying cooking salt with calcium chloride and magnesium chloride. If the problems due to the hygroscopic nature of these salts could be overcome the issue of fortified salts to volunteers resident in soft-water areas might well throw light on this subject.

Scunthorpe Health District,
Scunthorpe, Humberside

J S ROBERTSON

' Crawford, M D, and Crawford, T, Lancet, 1969, 2,

699.
2 Anderson, T W, Le Riche, W H, and Mackay, J S, New England fournal of Medicine, 1969, 280, 805

${ }^{3}$ Robertson, J S, Community Health, 1977, 8, 226.

$\mathbf{1 , 7 1 1 .}$

\section{Birth trauma in vaginal breech delivery}

SIR,-Your leading article (11 February, p 320) rightly emphasises the need for gentleness and skill in breech delivery. I hope it will not encourage young obstetricians to resort to caesarean section for most women with a breech presentation, whether disproportion is present or not, as section must increase the maternal risk.

I cannot believe that injury to the fetal head is caused by the obstetrician's fingers: these injuries must surely be due to forcible traction on the fetal trunk, particularly when the head is badly flexed. Traction with the MauriceauSmellie-Veit method maintains flexion at any pelvic level and, I believe, is superior to the Liverpool or Burns-Marshall procedure, which tends to extend the head in relation to the pelvis. Gentle suprapubic pressure on the head also tends to keep the head flexed as it passes through the brim.

Lövset's manoeuvre for delivering extended arms is very popular, but if the head becomes tightly wedged in the pelvis because of the extended arms this manoeuvre can cause fracture dislocation of the cervical spine, and the classical method of bringing down the arms should be employed if the head does not easily rotate with Lövset's manoeuvre.

\section{London W4}

\section{HuMPhREY ARTHURE}

SIR,-Your leading article (11 February p 320) draws attention to the importance of injury to the occipital bone in delivery of the after-coming head. The work of Yates, stressing the vulnerability of the cervical spine and vertebral arteries, was not limited to breech deliveries, however; he chose 60 fetuses without regard to the method of delivery.

I believe that a similar investigation is overdue into the effects of compression of the occipital bone in vertex presentations Neurosurgical investigation of adults suggests that neurological presentations in later life may result from birth injury around the foramen magnum, particularly Chiari type 2 malformation and communicating syringomyelia. In a recent series ${ }^{1} 2$ of over 100 cases questioned at a mean age of 44 , over half of the patients had some history of birth abnormality big babies, long labours, application of forceps, and being first children in the birth order were all more common than in a control series. The reason for this association is unclear: haemorrhage around the cerebellum may cause adhesions, hydrocephalus may result and produce cerebellar herniation, and compression of the head by forceps or excessive moulding of the cranial vault may similarly press the brain downwards. It seems at least as likely that some of the many skeletal abnormalities around the foramen magnum found in association with cerebellar herniation may be related to osseous damage at birth. These include basilar invagination, "coarctation" of the foramen magnum, occipitalisation of the atlas, Klippel-Feil deformity, abnormal rotations of the atlas and axis, and concave deformities of the occipital bone.

To what extent is the occipital bone moulded during labour? How frequent are fractures at this site? There are obviously ethical difficulties in, for example, carrying out lateral skull radiography on newborn babies. If difficultlabour babies only were $x$-rayed, then the range of normals would not be defined. Perhaps ultrasonics might allow safe investigation of moulding around the foramen magnum and answer the question whether it can recover and whether any treatment at that age might aid recovery.

BERNARD WILLIAMS

Midland Centre for Neurosurgery

and Neurology,

Warley, W Midland

Williams, B, Lancet, 1977, 2, 51.

Williams, B, Zeitschrift für Kinderchirurgie und Grenzegebiete, 1977, 22, 533 .

SIR,-Your leading article on birth trauma in vaginal breech delivery (11 February, p 320) omitted to mention specifically the breech with an extended head. This situation is an absolute indication for delivery by caesarean section. It should be emphasised that in every breech pregnancy extension of the fetal head should be sought before delivery. Only in this way can the rare but very tragic complication of spinal cord transection be avoided.

I BLUMENTHAL

Department of Paediatrics

Leighton Hospital,

\section{Heritability of blood pressure}

SIR,-In your leading article on this subject (21 January, p 127) data from some studies on twins and families are quoted and commented on. It is concluded that both genetic and environmental factors must be at work; what is still in doubt is the relative size of each component. It is also assumed that an unknown proportion $(30-80 \%)$ of the variability of blood pressure found in different people is an inherited characteristic and that this genetic component appears to be polygenetic.

The study of cardiovascular risk factors, including blood pressure, and their genetic determination has been one of the main subjects of the research programme for the Swedish Twin Registry (containing 10000 same-sexed twin pairs) ever since its establishment in 1961. Lundman, ${ }^{1}$ in his study on 196 male and female twin pairs, found a closer intrapair similarity for monozygotic than dizygotic pairs, especially among females, with regard to both systolic and diastolic blood pressure. However, in a later study by Liljefors $^{2}$ on 96 male twin pairs no difference was noted between monozygotic and dizygotic intrapair variances. The latter results were interpreted as giving no support to the assumption that blood pressure is governed by heredity. Similar conclusions have also been reached in other twin studies conducted by Downie et $a l^{3}$ and Mathers et al. ${ }^{4}$ 